\title{
PROPRIEDADES DAS ARGAMASSAS DE CAL COM ADIÇÃO DE GRUDE DE GURIJUBA (Arius spp.)
}

\author{
Manuella Araújo de Souza ${ }^{1}$
}

\author{
Daniel Véras Ribeiro ${ }^{2}$
}

Cybèle Celestino Santiago $^{3}$

\begin{abstract}
RESUMO
No estado brasileiro do Pará, segundo a tradição oral, a cola obtida da bexiga natatória do peixe gurijuba (Arius spp.), popularmente conhecida como "grude de gurijuba", teria sido utilizada para melhorar as propriedades das argamassas de cal de edificações antigas, entre os séculos XVII e XIX. No presente estudo, o "grude de gurijuba" (GG) foi adicionado às argamassas de cal nos teores de $2 \%$ e 5\%, em relação à massa do aglomerante, para que fosse observada a efetiva influência deste aditivo. Após a caracterização dos materiais envolvidos, moldaram-se corpos de prova que tiveram suas propriedades comparadas às das amostras de referência (sem GG) quanto à densidade e porosidade aparentes, resistência à tração na flexão e à compressão axial (NBR 13279:2005), absorção de água por capilaridade (NBR 15259:2005) e alterabilidade por sulfato de sódio (especificação LNEC E 238:1971). Os resultados obtidos foram bastante satisfatórios, mostrando a viabilidade técnica do uso do GG como aditivo em argamassas de cal e reforçando a tese quanto ao uso deste material em edificações antigas.
\end{abstract}

PALAVRAS-CHAVE: Argamassas. Cal. Aditivo orgânico. Gurijuba. Grude.

\section{PROPERTIES OF LIME MORTAR WITH ADDITION OF GRUDE OF GURIJUBA (Arius spp.)}

\footnotetext{
${ }^{1}$ Arquiteta e Urbanista, Universidade Federal da Bahia, Doutoranda do PPGAU. manuellasz@gmail.com

${ }_{2}^{2}$ Engenheiro Civil, Universidade Federal da Bahia, Professor Adjunto. verasribeiro@hotmail.com

${ }^{3}$ Arquiteta e Urbanista, Universidade Federal da Bahia, Professora Associada. cybele@ufba.br
} 


\title{
Periódica Eletronica ISSN 1980-0827

\begin{abstract}
In Brazilian state of Pará, according to oral tradition, the glue obtained from fish swim bladder gurijuba (Arius spp.), Popularly known as "grude of gurijuba" would have been used to improve the properties of lime mortars of old buildings, between the seventeenth and nineteenth centuries. In this study, the "grude of gurijuba" (GG) was added to lime mortars in amounts of $2 \%$ to $5 \%$ by mass of lime and influence of the additive was observed. After the characterization of the materials involved. Specimens were prepared and tested and had their properties compared to those of the reference sample (without GG) for density and apparent porosity, tensile strength in bending and axial compression (NBR 13279:2005, water absorption by capillarity action (NBR 15259:2005) and resistance to salt's attack (LNEC E 238:1971 specification). The results were quite satisfactory, showing the technical feasibility of using GG as an additive in lime mortar and reinforcing the thesis regarding the use of this material in old buildings.
\end{abstract}

KEY-WORDS: Mortars. Lime. Organic additive. Gurijuba. Grude.

\section{PROPIEDADES DE MORTERO DE CAL CON ADICIÓN DE GRUDE GURIJUBA (Arius spp.)}

\begin{abstract}
RESUMEN
En el estado brasileño de Pará, según la tradición oral, el pegamento obtenido de la vejiga del pez gurijuba (Arius spp.), popularmente conocido como "grude de gurijuba" habría sido utilizado para mejorar las propiedades de los morteros de cal de edificios antiguos, entre los siglos XVII y XIX. En este estudio, se añadió el "grude de gurijuba" (GG) a los morteros de cal en cantidades de $2 \%$ a $5 \%$ en peso del aglutinante, de manera que se observó la influencia efectiva del aditivo. Después de la caracterización de los materiales, fueron moldeados especímenes que tuvieron sus propiedades comparadas con los de la muestra de referencia (sin GG) para la densidad y porosidad aparente, resistencia a la tracción a la flexión y compresión axial (NBR 13279:2005), la absorción de agua por capilaridad (NBR 15259:2005) y resistencia a ataque de sales (LNEC E 238:1971). Los resultados fueron bastante satisfactorios, demostrando la viabilidad técnica de utilizar GG como aditivo en morteros de cal y reforzar la tesis sobre el uso de este material en los edificios antiguos.
\end{abstract}

PALABRAS-CLAVE: Morteros. Cal. Aditivo orgánico. Gurijuba. Grude.

\section{INTRODUÇÃO}

Pode-se definir argamassa como o material construtivo resultante da mistura de uma pasta formada por aglomerante (cal ou cimento, por exemplo) e água e a ela adicionada um agregado como a areia. Nas argamassas, o aglomerante é o constituinte ativo da mistura e a areia atua como material de enchimento, contribuindo com a estabilidade volumétrica (reduzindo a retração na secagem) e além de facilitar a passagem do anidrido carbônico do ar, permitindo a carbonatação do hidróxido de cálcio (SICHIERI et al, 2008). A carbonatação é fundamental nas argamassas de cal, pois permite que se tornem mais rígidas e duráveis. 
De acordo com Santiago (1991), as argamassas podem diferir quanto à composição, ao traço (proporção entre constituintes) e à qualidade dos materiais empregados. A maior parte das argamassas desenvolvidas há alguns séculos, utilizava a cal como ligante, areia, água, eventualmente argila e a elas certas vezes eram incorporados aditivos que tinham como objetivo melhorar suas propriedades e variavam de acordo com a disponibilidade nas proximidades do edifício a ser construído, podendo ser orgânicos (como óleos, gorduras, ceras, sangue animal, urina, ovos, açúcar, óleo de linhaça, etc) ou inorgânicos (como cinzas vulcânicas).

Quando se pesquisa argamassas antigas é comum tomar como referência as recomendações do arquiteto e tratadista romano, Vitrúvio (2007), datadas de 27 a.C. Segundo o referido autor, as argamassas deveriam ser produzidas na proporção de 1:3, ou seja, para cada parte de cal, três partes de areia de jazida ou 1:2 quando utilizada areia de origem marinha ou fluvial.

Entende-se que o estudo de argamassas antigas é relevante por permitir o conhecimento de técnicas utilizadas na época mas, atualmente em desuso, e que podem facilitar a recuperação e intervenções restaurativas em monumentos degradados. Além deste fato, o estudo deste material construtivo antigo permite contribuir com o desenvolvimento de tecnologias de construção alternativas de modo a evitar o uso de materiais danosos ao meio ambiente, tais como o cimento, cuja produção gera cerca de uma tonelada de gás carbônico para cada tonelada produzida do aglomerante, o que equivale a cerca de $5-8 \%$ de toda a emissão mundial deste gás (SCRIVENER e KIRKPATRICK, 2007; WBCSD, 2009). Por sua vez, o gás carbônico contribui com o efeito estufa, a chuva ácida e o aquecimento global (RASOOL; SCHNEIDER, 1971).

Considerando que o uso de aditivos variava conforme a região e os materiais disponíveis, decidiu-se selecionar um material oriundo do litoral norte brasileiro, historicamente indicado como possível aditivo orgânico para argamassa: o "grude" da gurijuba (Arius spp.), cola obtida da bexiga natatória do peixe (órgão responsável por regular seu nível de profundidade). O principal objetivo do estudo deste aditivo é identificar as propriedades da cola proteica da gurijuba e a sua influência no desempenho das argamassas no intuito de obter material construtivo durável e 
compatível com os materiais antigos, podendo ser utilizado nas intervenções ou restaurações de edifícios históricos.

\section{MATERIAIS E MÉTODOS}

\subsection{Materiais}

Para confecção dos corpos de prova de argamassa, utilizou-se como aglomerante cal hidratada da marca Trevo, tipo $\mathrm{CH}-1$ (alta pureza), conforme as diretrizes da norma brasileira NBR 7175:2003.

Como agregado miúdo, foi utilizada areia de jazida, normalmente comercializada na cidade de Salvador, Bahia. Esta areia foi caracterizada quanto à sua massa unitária, massa específica e distribuição granulométrica.

O peixe gurijuba é encontrado em abundância no litoral norte do Brasil, mais especificamente na região do Salgado, na qual o município de Vigia (Pará) está inserido. Este peixe possui uma bexiga natatória, conhecida popularmente como "grude" (figura 1), do qual é extraída uma cola que apresenta propriedades aglutinantes - fato que dá indícios quanto ao seu uso como aditivo.

Figura 1: Grude de gurijuba seco

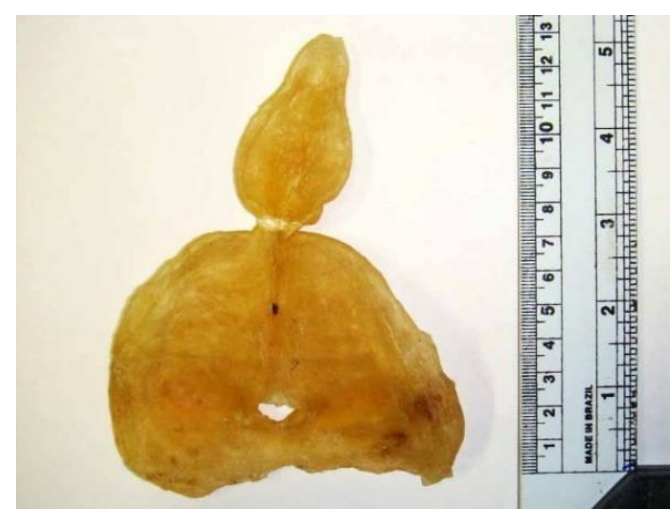

Alguns habitantes da região relatam o uso do "grude" como aditivo orgânico nas argamassas produzidas entre os séculos XVII e XIX. A tradição oral indica que as argamassas aditivadas com a cola proteica tenham sido utilizadas no reboco das ruínas franciscanas da praia de Joanes, na llha do Marajó (séc. XVII), na Capela do 
Senhor dos Passos e na Igreja Matriz Madre de Deus, ambas do século XVIII e situadas em Vigia. O "grude" de gurijuba teria sido empregado, ainda, na colagem de pastilhas do piso em mosaico existente no hall central do Theatro da Paz (fim do século XIX), em Belém. O "grude" da gurijuba teria sido usado em substituição ao óleo de baleia, em falta, devido à dificuldade de comércio entre as capitanias, de acordo com os relatos de moradores da cidade de Vigia. Dessa maneira, caracterizou-se o material e suas propriedades foram devidamente estudadas.

\subsection{Métodos}

A caracterização dos materiais envolveu análises dos parâmetros físicos tais como a área superficial BET, determinação da massa específica dos agregados miúdos (NM 52:2009), determinação da massa unitária e do volume de vazios dos agregados (NBR NM 45:2006), absorção (NBR NM 30:2001) e determinação da composição granulométrica (NBR NM 248:2003).

Após a caracterização física das matérias-primas, partiu-se para a elaboração do traço (relação entre os componentes da mistura, em massa). $O$ traço escolhido seguiu recomendações de Vitrúvio (2007) para areia de jazida, ou seja, 1:3 (cal : areia), medidos em volumeErro! Fonte de referência não encontrada.. Ao converter as medidas considerando a massa unitária da cal e da areia disponíveis, o resultado foi 1:8,4:2 (cal : areia : água), em massa. A cal em pasta foi inserida na mistura para reproduzir o processo de fabricação tradicional das argamassas de cal.

A etapa seguinte envolveu a moldagem de lotes de corpos de prova de referência (sem o grude), com adição de $2 \%$ de cola e com adição de $5 \%$, em relação à massa de cal. A cola foi adicionada à água de amassamento e as matérias-primas misturadas mecanicamente em argamassadeira durante dois minutos, sendo a mistura, a seguir, vertida em moldes prismáticos com dimensões de $4 \times 4 \times 16 \mathrm{~cm}$. Após isso, foram vibradas durante 60 segundos, na frequência de $60 \mathrm{~Hz}$. A metodologia para a moldagem dos corpos de prova seguiu as normas NBR 13279:2005 e os ensaios foram realizados segundo as NBR 15259:2005, NBR NM 46:2006. A caracterização dos corpos de prova deu-se após 150 dias. 
Espera-se que um material construtivo como a argamassa apresente, dentre outras características, resistência mecânica satisfatória para que possa desempenhar sua função. Tradicionalmente, sabe-se que as argamassas não suportam altas cargas nos ensaios de tração e flexão, mas por outro lado, apresentam valores maiores na compressão axial (cerca de dez vezes o limite de tração na flexão) (RIBEIRO, 2010).

O limite de resistência à compressão simples é uma das propriedades mais importantes em materiais frágeis, como as cerâmicas e as argamassas, e é cerca de dez vezes superior ao limite de resistência à tração e à flexão. Numericamente, é calculado dividindo a carga máxima suportada pelo corpo de prova até a ruptura, por sua secção original. Para a determinação da resistência à tração na flexão, fez-se o ensaio tradicionalmente conhecido por flexão a três pontos, onde o corpo de prova prismático é apoiado sob dois pontos, com o rompimento sendo efetuado devido à ação de uma carga na região central da amostra.

A absorção de água por capilaridade em argamassas consiste em uma propriedade relevante, pois uma absorção excessiva de água pode facilitar a proliferação de fungos e bactérias danosos ao usuário do edifício e ao próprio material, além de outros problemas, como o descolamento da argamassa e/ou do revestimento, a cristalização de sais e o destacamento da camada pictórica. De acordo com Ribeiro (2010) é, também, um indicador de maior difusão de elementos e soluções para o interior da mistura e, em consequência, aumenta as chances de ocorrência de corrosão (para o caso de estruturas armadas).

Para a determinação da absorção de água por capilaridade, os corpos de prova utilizados (três corpos de prova por composição) devem estar com 150 dias de idade para que a carbonatação da cal seja razoavelmente efetivada. Inicialmente, são secos em estufa por 24 horas e, após isso, resfriados à temperatura ambiente e têm suas massas determinadas.

Com os corpos de prova sobre suportes, preenche-se com água a bandeja do recipiente de ensaio, de modo que o nível de água permaneça constante e igual a 7 $( \pm 1) \mathrm{mm}$ da base inferior do recipiente, evitando a molhagem de outras superfícies do corpo de prova. Durante o ensaio, determina-se a massa dos corpos de prova com intervalos de tempo normalizados pela NBR 15259:2005. 
Calcula-se, dessa forma, o coeficiente de absorção capilar, que representa a massa de água absorvida por metro quadrado da argamassa em contato com a água, em função da raiz quadrada do tempo decorrido até atingir este ponto de absorção. Numericamente, este valor corresponde ao coeficiente angular da reta proveniente do gráfico "absorção $\left(\mathrm{kg} / \mathrm{m}^{2}\right) \times$ raiz do tempo $\left(\mathrm{min}^{0,5}\right)$ " até que seja atingido o ponto de saturação, como pode ser visto na Figura 2.

Figura 2: Curva de absorção capilar de água em função da raiz quadrada do tempo, segundo a NBR 15259, para determinação do coeficiente de absorção capilar ( $\operatorname{Tg} \varphi)$

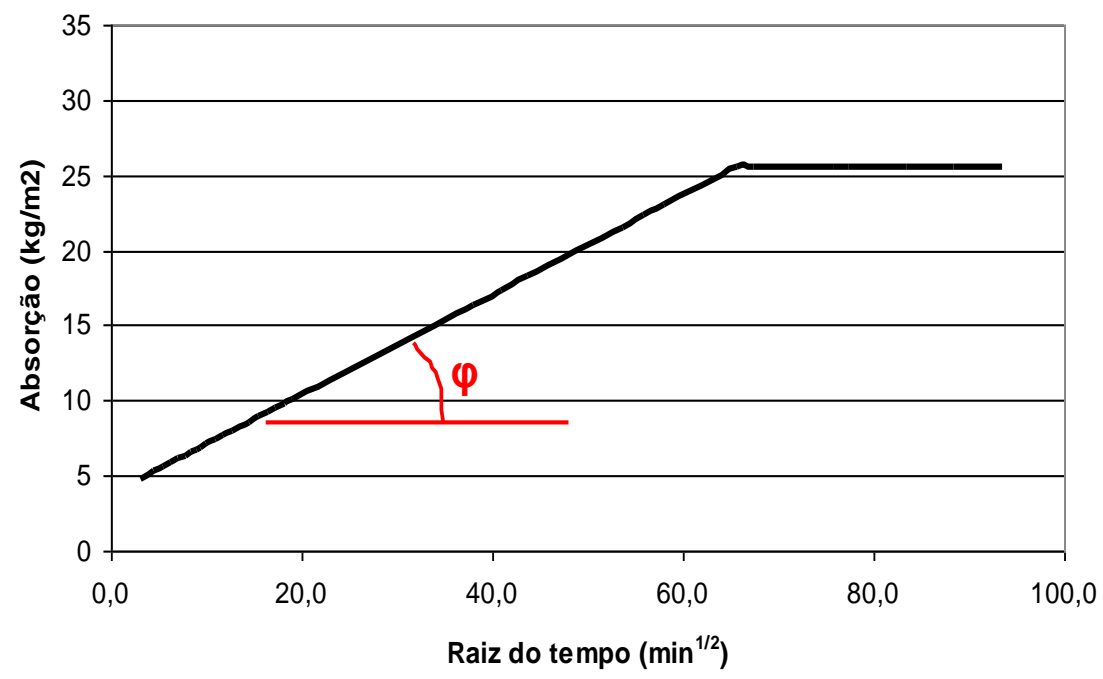

O ensaio de alterabilidade por sulfato de sódio objetiva simular a ação das intempéries às quais as argamassas podem estar submetidas (ciclos seco-úmido, eflorescências salinas, gelo-degelo). Assim, os corpos de prova executados em laboratório passam por ciclos de molhagem em solução saturada de sulfato de sódio anidro $\left(\mathrm{Na}_{2} \mathrm{SO}_{4}\right)$ e secagem forçada em estufa à $70 \stackrel{\circ}{\circ}$, permanecendo por 24 horas em cada situação, conforme a especificação E 238 (LNEC, 1971) do Laboratório Nacional de Engenharia Civil (LNEC), Lisboa, Portugal.

O sulfato de sódio é considerado um dos sais mais agressivos na conservação das estruturas. Quando em contato com materiais porosos, o sal presente em uma solução deposita-se nos poros da estrutura de materiais como a argamassa e pode se recristalizar, causando a degradação destes (fraturas, esfarelamento etc.), devido às tensões que provoca. 


\section{RESULTADOS}

\subsection{Caracterização das matérias-primas}

A cal utilizada apresentou massa unitária de $0,41 \mathrm{~kg} / \mathrm{dm}^{3}$ e sua massa específica foi igual a $2,23 \mathrm{~kg} / \mathrm{dm}^{3}$. A distribuição do tamanho de partículas da areia utilizada no presente estudo é mostrada na Figura 3. A NBR 7211:1997 classifica as areias em quatro faixas, denominadas muito fina, fina, média e grossa. Na mesma figura, podemos ver os limites inferior e superior que caracterizam uma areia como "muito fina" (faixa 1). Como pode-se perceber, todas as porções da areia utilizada estão dentro da faixa em questão. A caracterização física da areia é mostrada na Tabela 3.

Figura 3: Distribuição granulométrica classificada como "areia muito fina - faixa 1" (NBR 7211)

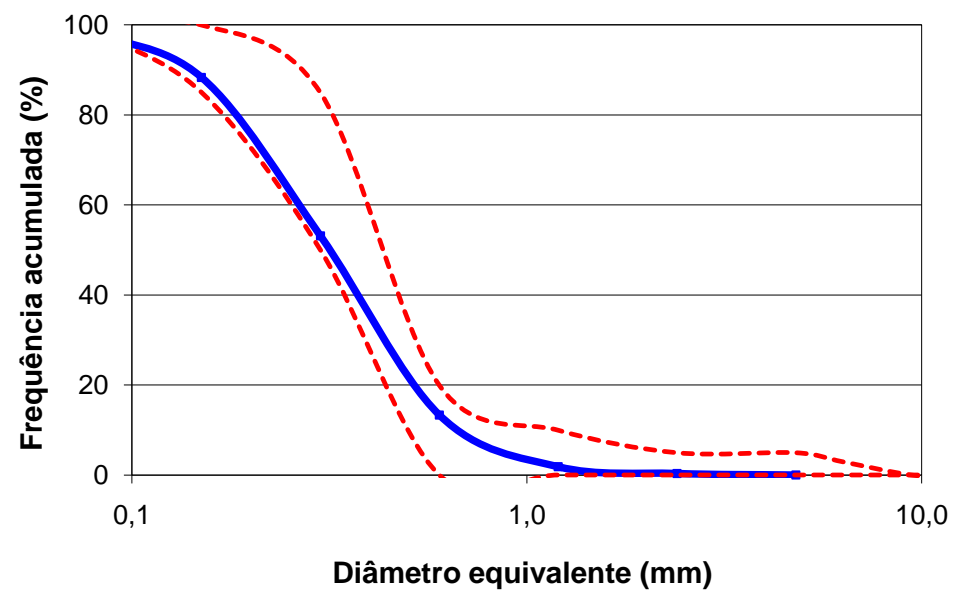

Tabela 3: Caracterização física da areia utilizada na produção das argamassas

\begin{tabular}{c|c} 
Grandeza & Resultado \\
\hline Área superficial & $0,68 \mathrm{~m}^{2} / \mathrm{g}$ \\
\hline Massa unitária & $1,48 \mathrm{~kg} / \mathrm{dm}^{3}$ \\
\hline Massa específica & $2,62 \mathrm{~kg} / \mathrm{dm}^{3}$ \\
\hline Módulo de finura & 1,57 \\
\hline Dimensão máxima característica & $1,18 \mathrm{~mm}$ \\
\hline Absorção & $0,10 \%$ \\
\hline Teor de materiais pulverulentos & $1,00 \%$ \\
\hline
\end{tabular}

O "grude" de Gurijuba foi pulverizado e sofreu pré-tratamento, permanecendo por 24 horas, em solução aquosa, com concentração de 10\% (em massa), sendo 
posteriormente aquecido à temperatura de cerca de $40{ }^{\circ} \mathrm{C}$, atingindo a consistência de uma cola (Figura 4). A seguir, esta cola proteica foi misturada à água de amassamento, nos teores de $2 \%$ e $5 \%$ em relação à massa de cal.

Figura 4: Processo de tratamento da bexiga natatória da gurijuba para uso como aditivo às argamassas de cal. (A) "Grude" de gurijuba seco, (B) após pulverização, (C) imerso em água a $40 \stackrel{\circ}{\circ}$ e (D) sua consistência final (cola)
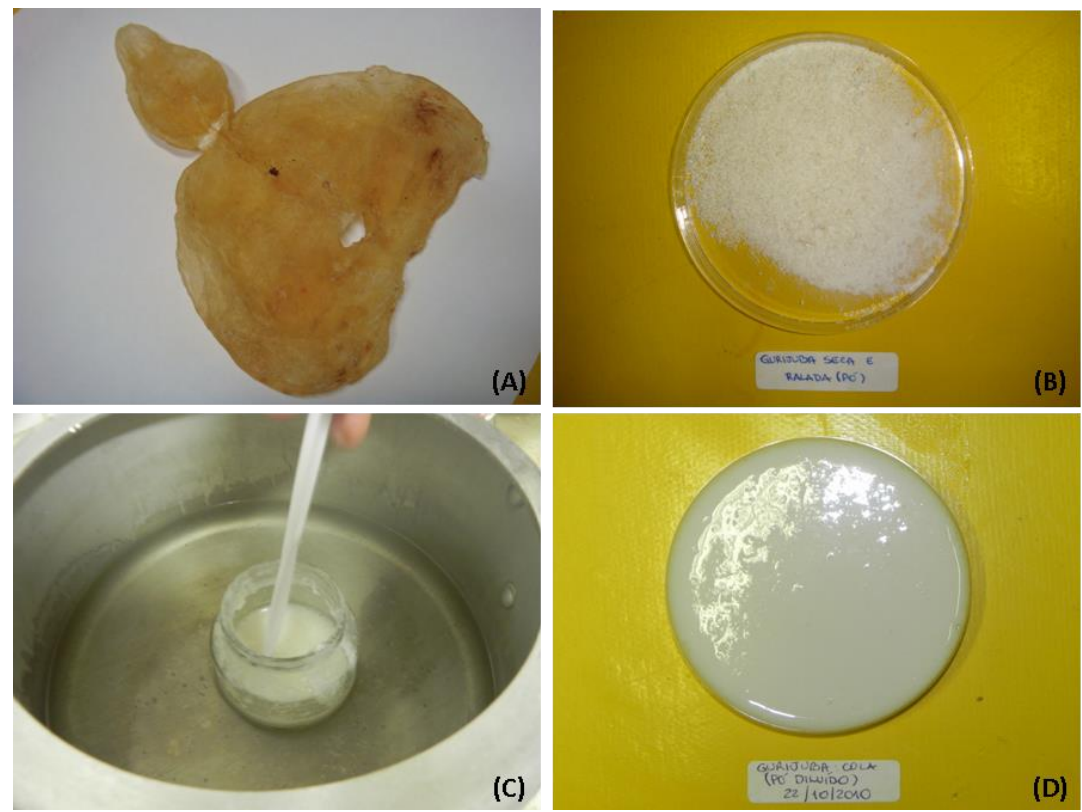

\subsection{Caracterização das argamassas de cal}

\subsubsection{Porosidade e densidade aparentes (ensaio com água)}

Este ensaio foi realizado apenas aos 300 dias de idade ${ }^{4}$, quando duas propriedades foram avaliadas: a porosidade e a densidade aparente das argamassas de cal executadas em laboratório. Na figura 5, percebe-se que o aumento no teor de cola inserido na argamassa estudada não oferece contribuições significativas para a porosidade e densidade do material construtivo, pois o gráfico demonstra certa estabilidade de valores.

\footnotetext{
${ }^{4} \mathrm{O}$ ensaio só foi realizado aos 300 dias, pois, quando se decidiu que seria conveniente a sua execução, os CPs pertencentes ao primeiro lote já tinham sido ensaiados.
} 
Figura 5: A) Porosidade e B) densidade aparentes das argamassas de cal (aos 300 dias) em função do teor de cola adicionado

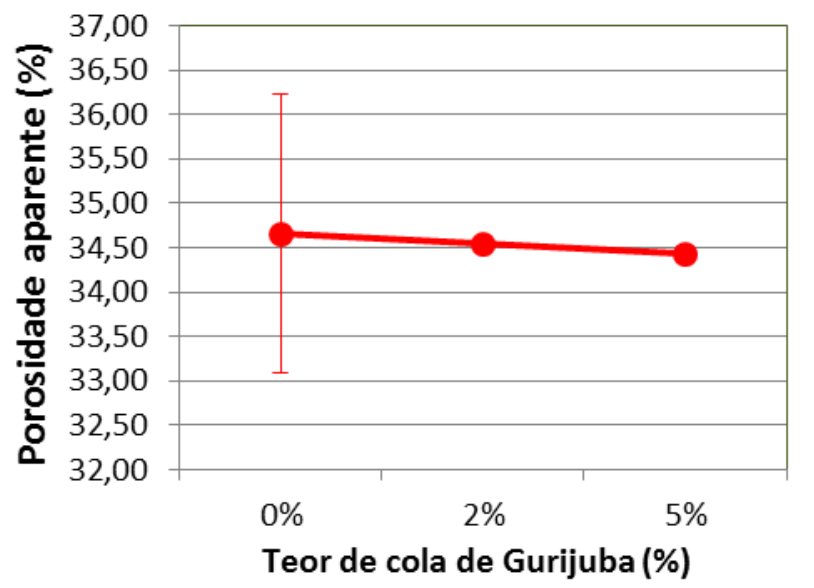

(A)

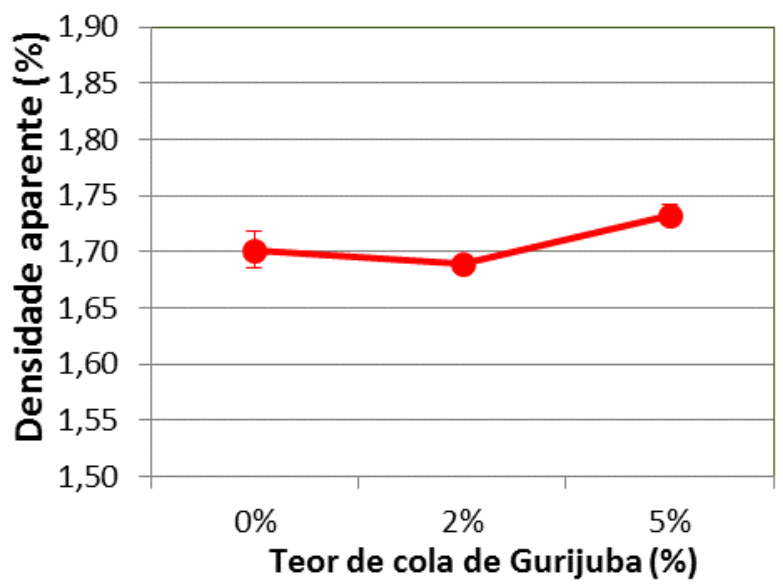

(B)

\subsubsection{Resistência mecânica (simples e à tração na flexão)}

Os corpos de prova foram ensaiados quanto à resistência à tração na flexão e compressão simples, de acordo com a NBR 13279:2005, após 150 dias de cura, a fim de avaliar o desempenho das mesmas e o efeito da presença do "grude" nos teores de $2 \%$ e $5 \%$. Os resultados de resistência à tração na flexão e à compressão simples são apresentados na Figura 6.

Figura 6: A) Resistência à tração na flexão e B) Resistência à compressão das argamassas de cal (150 dias) em função do teor do aditivo estudado.

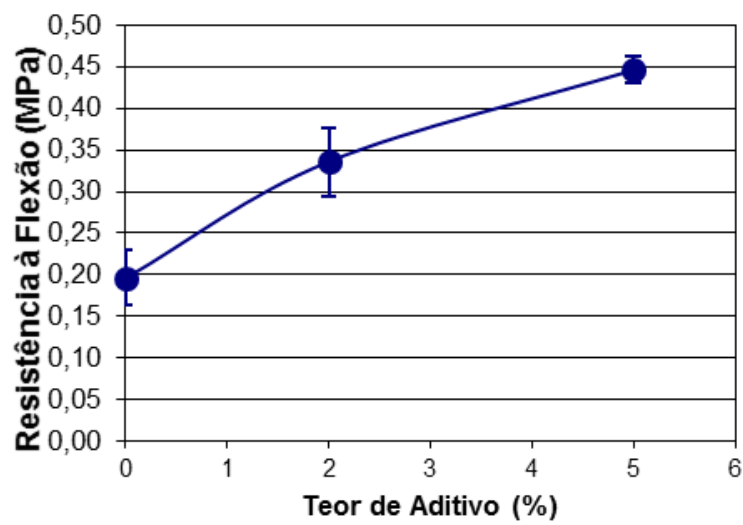

(A)

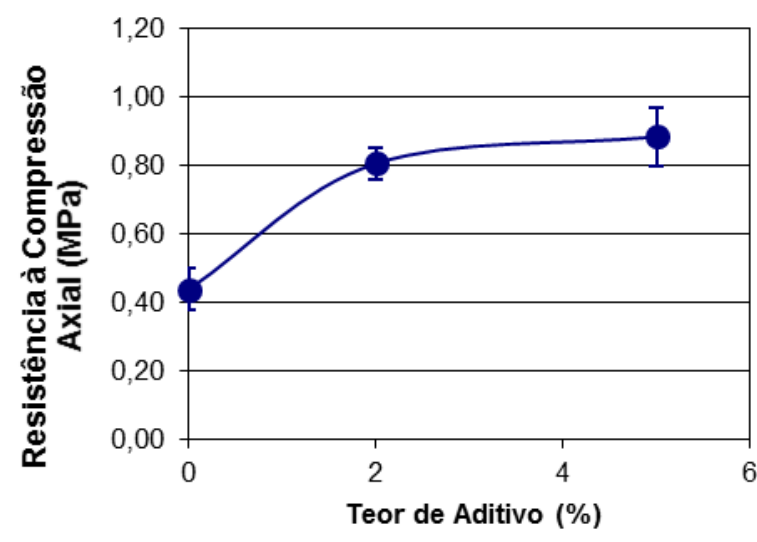

(B) 
Observa-se nos resultados apresentados na Figura 6 que a adição da cola produzida com o "grude" de gurijuba aumentou consideravelmente a resistência mecânica das argamassas de cal, indicando uma razoável capacidade aglomerante deste material.

Dentre os resultados, alguns aspectos chamam a atenção: i) o aumento da resistência à tração na flexão das argamassas de cal foi de cerca de $125 \%(0,20 \mathrm{MPa}$ versus $0,45 \mathrm{MPa}$ ) para um teor de $5 \%$ de adição da cola; ii) a resistência à compressão simples teve aumento de quase $100 \%$ após a adição de $2 \%$ de cola, mas, pouco se modificou quando foram incorporados $5 \%$ do aditivo. Sugere-se a posterior realização de ensaios com corpos de prova aditivados a 1\%, 1,5\% e 2,5\% de cola, para verificar se essa estabilidade se configura, a partir da quantidade de $2 \%$ de cola ou os valores já se estabilizam a partir de 1\%. Estes resultados merecem destaque e dão indícios quanto à qualidade deste aditivo. No entanto, por ser tratar de material orgânico, é válido observar seu comportamento após longos períodos, uma vez que a degradação pode ser acentuada.

\subsubsection{Absorção de água por capilaridade}

Com o intuito de verificar a influência do aditivo de gurijuba na microestrutura das argamassas de cal, analisou-se a absorção de água por capilaridade das amostras. Os resultados de absorção de água são indicativos indiretos da porosidade do material. Isto é, a maior absorção de água, também pode ser entendida como maior porosidade da argamassa. Segundo estudos realizados por Ribeiro et al (2011), uma maior porosidade aparente costuma ter como consequência maior porosidade total.

Assim, pode-se supor que a inserção do aditivo tende a aumentar o diâmetro dos capilares ou até obstrui-los, reduzindo a absorção capilar em função do aumento na proporção da cola na argamassa para a idade de 150 dias $\left(0,39 \mathrm{~g} / \mathrm{dm}^{2} \cdot \mathrm{min}^{0,5}\right.$ para $0 \%$ contra $0,24 \mathrm{~g} / \mathrm{dm}^{2} \cdot \mathrm{min}^{0,5}$ para $5 \%$ do aditivo).

Ao analisar a idade de 300 dias, nota-se certa estabilidade de valores entre 0 teor de $5 \%$ de cola e a argamassa de referência ( $0 \%$ ): por volta de $0,11 \mathrm{~g} / \mathrm{dm}^{2} \cdot \mathrm{min}^{0,5}$. Apesar disso, estranhamente, o valor encontrado para $2 \%$ de aditivo é superior aos 
demais, atingindo cerca de $0,16 \mathrm{~g} / \mathrm{dm}^{2} \cdot \mathrm{min}^{0,5}$, indicando aumento de $45 \%$ na absorção, conforme figura 7 .

Figura 7: Coeficientes de absorção capilar das argamassas de cal aos 150 e 300 dias em função do teor do aditivo estudado

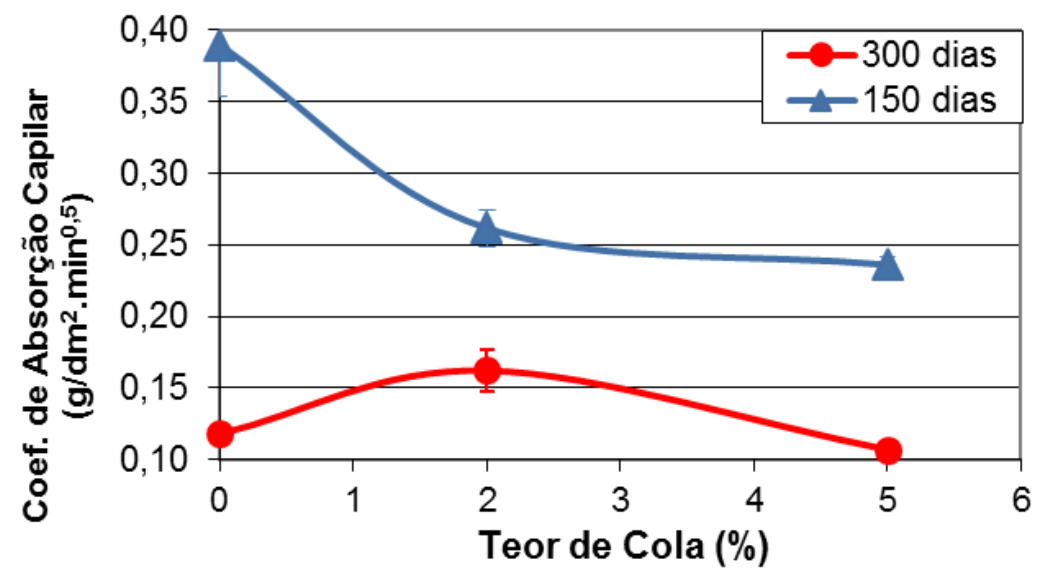

\subsubsection{Alterabilidade por sulfato de sódio $\left(\mathrm{Na}_{2} \mathrm{SO}_{4}\right)$}

Os resultados obtidos neste ensaio são demonstrados na figura 8. Tanto aos 150 como aos 300 dias, os corpos de prova aditivados com cola a $5 \%$ resistiram a maior número de ciclos de molhagem e secagem em solução saturada de sulfato de sódio e foi avaliada a perda de massa em função do número de ciclos.

A avaliação qualitativa deste ensaio indica que, aos 150 dias (figura 8), a argamassa a $5 \%$ de aditivo resistiu seis vezes mais que a de referência e, aproximadamente, duas vezes mais do que a argamassa contendo $2 \%$ de cola. 
Figura 8: Variação de massa do $\mathrm{CP}$ em função do número de ciclos de molhagem / secagem aos 150 dias

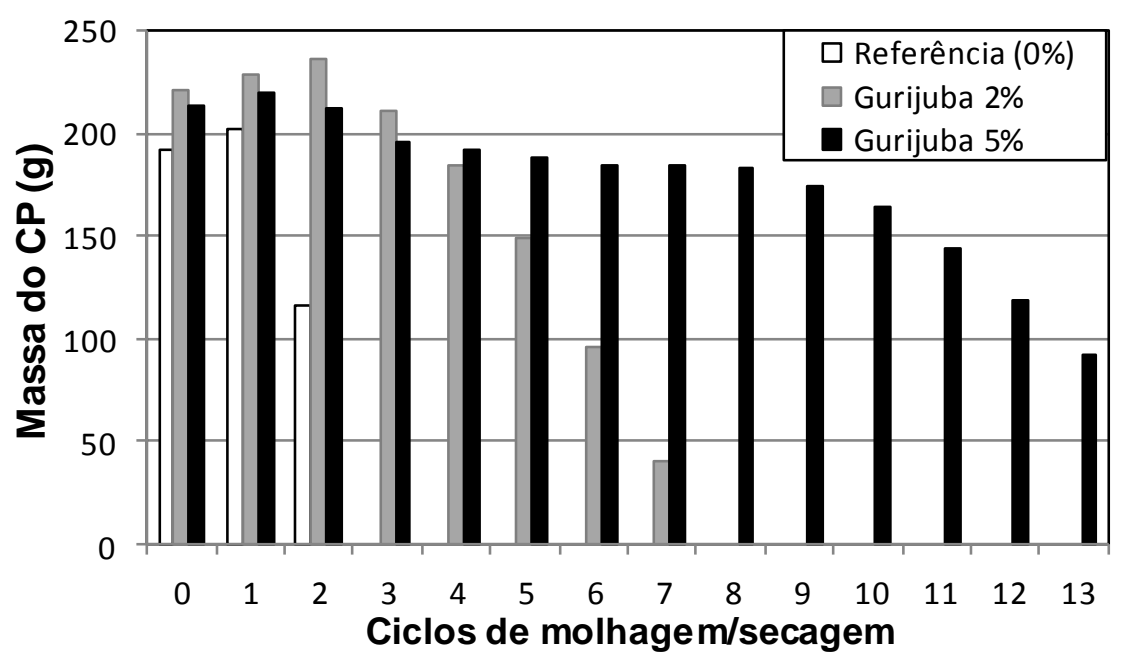

Aos 300 dias, as argamassas com 5\% de aditivo suportaram quase o mesmo número de ciclos que as aditivadas com $2 \%$ de cola de gurijuba, superando estas em um único ciclo (figura 9). A argamassa de referência também apresentou boa resistência ao ataque de sais, degradando-se completamente após o oitavo ciclo.

Figura 9: Variação de massa do $\mathrm{CP}$ em função do número de ciclos de molhagem / secagem aos 300 dias

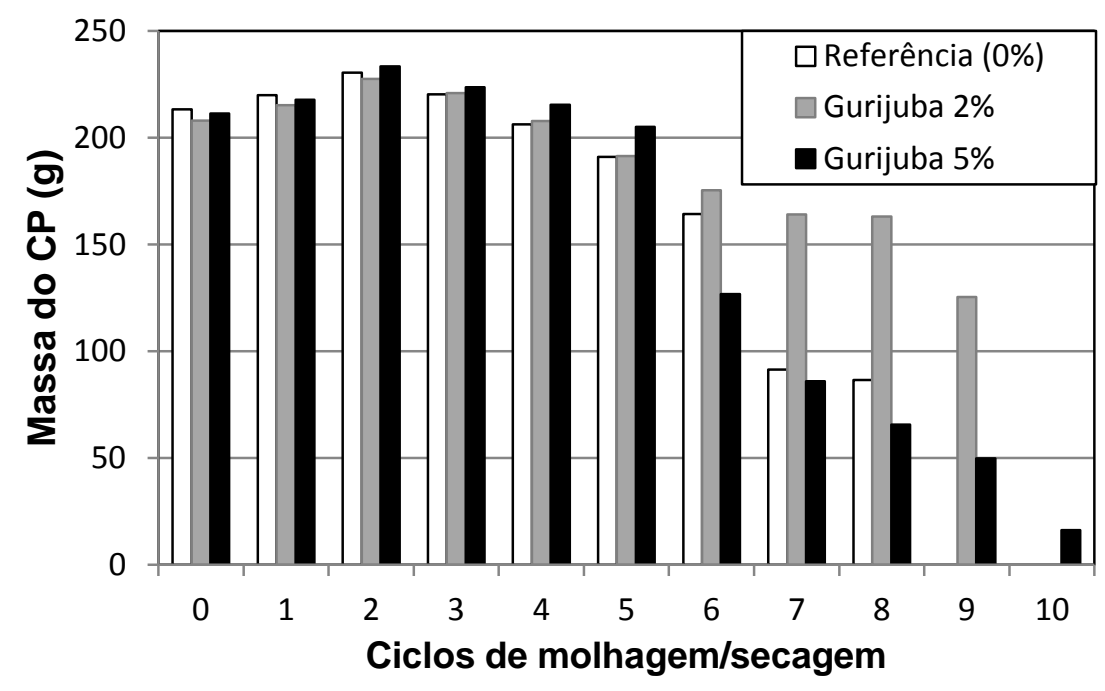




\section{CONCLUSÕES}

Com base nos resultados obtidos na investigação acerca das argamassas estudadas, verificou-se que as argamassas aditivadas com grude de gurijuba apresentaram, em geral, um bom comportamento, especialmente em relação às resistências mecânica à tração na flexão e à compressão axial, à alterabilidade por sulfato de sódio (envelhecimento acelerado) e à absorção de água por capilaridade, que se configuram em características relevantes quando se trata da proteção de alvenarias históricas.

Acredita-se que a cola proteica tenha provocado na argamassa um aumento na coesão entre as partículas por, aparentemente, não influenciar na porosidade nem na densidade, justificando a elevação nos resultados de resistência. É possível, ainda, que a cola tenha obstruído os capilares, o que explicaria a redução na absorção de água, sem redução da porosidade da argamassa.

Os resultados merecem destaque e dão indícios quanto à qualidade do referido aditivo e ao seu possível uso em argamassas de edificações paraenses entre os séculos XVII e XIX, configurando-se no primeiro passo para o estudo desta cola proteica em argamassas de cal. Entretanto, por se tratar de material orgânico, sugerese que a pesquisa seja aprofundada e que o comportamento deste aditivo seja monitorado por longos períodos, pois a degradação das argamassas de cal com "grude de gurijuba" pode ser acentuada.

\section{REFERÊNCIAS}

ABNT. NBR 7175: Cal hidratada para argamassas - Requisitos. Rio de Janeiro, 2003.

ABNT. NBR 7211: Agregados para concreto. Rio de Janeiro, 1997.

ABNT. NBR 13279: Argamassa para assentamento e revestimento de paredes e tetos Determinação da resistência à tração na flexão e compressão. Rio de Janeiro, 2005.

ABNT NBR 15259: Argamassa para assentamento e revestimento de paredes e tetos Determinação da absorção de água por capilaridade e do coeficiente de capilaridade. Rio de Janeiro, 2005. 
ABNT NBR NM 30: Agregado miúdo - Determinação da absorção de água. Rio de Janeiro, 2001.

ABNT NBR NM 45: Agregados - Determinação da massa unitária e do volume de vazios. Rio de Janeiro, 2006.

ABNT NBR NM 46: Agregados - Determinação do material fino que passa através da peneira 75 um, por lavagem. Rio de Janeiro, 2003.

ABNT NBR NM 52: Agregado miúdo - Determinação da massa específica e massa específica aparente. Rio de Janeiro, 2009.

ABNT NBR NM 248: Agregados - Determinação da composição granulométrica. Rio de Janeiro, 2003.

LNEC E 238. Agregado: Ensaio de alteração pelo sulfato de sódio ou pelo sulfato de magnésio. Lisboa: 1971.

Rasool, S. I. e Schneider, S. H. Atmospheric Carbon Dioxide and Aerosols: Effects of Large Increases on Global Climate. Science Magazine, 1971: Vol. 173. no 399. Disponível em: <http://www.sciencemag.org/content/173/3992/138.full.pdf> Acesso em: 26 mai. 2014.

Ribeiro, D.V. Influência da adição da lama vermelha nas propriedades e na corrosibilidade do concreto armado. São Carlos: UFSCar, 2010.

Ribeiro, D. V; Labrincha J. A.; Morelli, A. R. Chloride Diffusivity in Red Mud-Ordinary Portland Cement Concrete Determined by Migration Tests. Materials Research. Vol. 14, no 2, Maio/Junho 2011.

Santiago, C. C. Aditivos orgânicos em argamassas antigas. Dissertação de mestrado apresentada ao PPGAU da UFBA (não publicada). Salvador, 1991.

Scrivener K. I. e Kirkpatrick R. J. Innovation in use and research on cementitious material. In: 12th International Congress of Chemistry of Cement. Anais... Montreal, Canada, 2007.

Sichieri, P. S.; Pablos, J. M.; Ferreira, O. P.; Rossignolo, J. A. e Caram, R. Materiais de Construção I: Aglomerantes Minerais, Agregados, Argamassas, Concretos e Dosagem. São Carlos: EESC-USP, Junho 2008.

Vitrúvio, M. L. Tratado de Arquitetura. Tradução, introdução e notas: M. Justino Maciel. São Paulo: Martins, 2007. Coleção Todas as Artes.

World Business Council for Sustainable Development (WBCSD) / International Energy Agency (IEA). Cement Technology Roadmap 2009-Carbon emissions reductions up to 2050. IEA, $2009.2 \quad$ Disponível em: <http://www.iea.org/publications/freepublications/publication/name,3862,en.html> Acesso em: 09 jun. 2014. 